\title{
Gap Junctional Intercellular Communication in Cells Isolated from Urethane-Induced Tumors in A/J Mice
}

\author{
ADINA VULTUR, ${ }^{1}$ EVANGELIA TOMAI, ${ }^{1}$ KATHERINE PEEBLES,${ }^{3}$ ALVIN M. MALKINSON,${ }^{3}$ \\ NICHOLAS GRAMMATIKAKIS, ${ }^{1}$ POH-GEK FORKERT, ${ }^{2}$ and LEDA RAPTIS ${ }^{1}$
}

\begin{abstract}
Studies using normal or neoplastically transformed established mouse lung epithelial cell lines revealed a reduction in gap junctional, intercellular communication (GJIC) with transformation. To determine the stage in tumor development at which GJIC is interrupted, we used the well-established model of lung tumors induced in strain A/J mice by urethane. In this system, tumor development follows a well-characterized pattern; hyperplasias, adenomas, and carcinomas are manifested at approximately 8,16 , and 40 weeks after urethane treatment, respectively. GJIC levels were examined using a novel technique where cells are grown on a glass slide, half of which is coated with electrically conductive, optically transparent, indium-tin oxide. An electric pulse that opens transient pores on the plasma membrane is applied in the presence of the fluorescent dye, Lucifer yellow, causing dye penetration into cells growing on the conductive part of the slide. Migration of the dye through gap junctions to nonelectroporated cells growing on the nonconductive area is then microscopically observed under fluorescence illumination. Unexpectedly, primary cells cultured from urethane-induced tumors, even late stage carcinomas, possessed extensive GJIC immediately upon isolation. Upon passage for several months however, these cells lost GJIC. These results suggest that the molecular changes that lead to the formation of the tumor in vivo are not sufficient to interrupt gap junctions. Propagation of tumor cells in culture induces additional alterations that can lead to gap junction closure.
\end{abstract}

\section{INTRODUCTION}

G AP JUNCTIONS ARE CLUSTERS of plasma membrane channels that serve as conduits for the passage of small molecules and ions between the interiors of cells (Goodenough et al., 1996). Gap junction channels open and close in a regulated manner. This "gating" is achieved through phosphorylation of connexins, the major gap junction proteins, and changes in intercellular $\mathrm{pH}$, calcium concentration, and redox status depending upon the particular connexin(s) (Bruzzone et al., 1996). Changes in gap junctional intercellular communication (GJIC) modulate proliferation and differentiation of normal cells. It has been postulated that a GJIC reduction facilitates abnormal growth, given that a number of activated oncogenes such as Src and Ras or tumor promotors interrupt gap junctions (Azarnia et al., 1988; De Feijter et al., 1992; Raptis et al., 1994). At the same time, GJIC reduction also accompanies the cessation of proliferation and differentiation of murine preadipocytes (Azarnia and Russell, 1985; Brownell et al., 1996). In the case of human lung carcinomas, examination of gap junctions in fresh tumor tissue by electron microscopy suggested that a tumor's ability to spread and metastasize is inversely related to its number of intercellular junctions visible by electron microscopy (McDonagh et al., 1991), but no functional gap junctions were found in cells cultured from a number of human lung cancer specimens (Tomai et al., 1988, 1999).

Primary lung tumors in mice have been used extensively to model human lung adenocarcinomas and provide insights into molecular events during carcinogenesis, due to their morphologic, histogenic, and molecular similarities (Malkinson, 2001). Studies using normal versus neoplastically transformed established mouse lung epithelial cell lines revealed a reduction in GJIC upon transformation (Cesen-Cummings et al., 1998). However, since the immortalization process itself may have al-

${ }^{1}$ Departments of Microbiology and Immunology and Pathology, and ${ }^{2}$ Anatomy and Cell Biology, Queen's University, Kingston, Ontario, Canada.

${ }^{3}$ Department of Pharmaceutical Sciences, University of Colorado Health Sciences Center, Denver, Colorado. 
tered the cells, a correlation between GJIC and the characteristics of the cells when they were in their natural environment as part of normal tissue or a naturally occurring tumor remains to be established; primary cultures may be more representative of the in vivo situation. Moreover, to determine when GJIC is interrupted, it is necessary to examine GJIC in cells at different stages of neoplastic development. To address these questions, we used the well-established model of lung tumors induced in strain A/J mice by urethane. This strain displays enhanced susceptibility to chemical carcinogens, perhaps due to overexpression of a Ki-ras allele (Chen et al., 1994), and offers a highly reproducible model of tumor progression (Malkinson, 1992). Tumor development follows a well-characterized pattern; hyperplasias, adenomas, and carcinomas are manifested at approximately 8,16 , and 40 weeks after urethane treatment, respectively (Forkert et al., 1996). Lung adenomas and carcinomas grow in solid or papillary patterns. Solid tumors are derived from alveolar type II cells (Thaete et al., 1987); the cell of origin of papillary tumors has not been established, but it has been proposed that they may originate from either the alveolar type II or the nonciliated bronchiolar Clara cells (Forkert et al., 1996). To examine the effects of tumor progression upon GJIC, we measured Lucifer yellow dye transfer and connexin 43 expression in cells cultured from tumors at different stages after urethane administration, and compared with primary cultures derived from their cells of origin.

Assays to detect GJIC in cultured cells include the introduction of nontoxic, fluorescent dyes such as Lucifer yellow, into a cell usually through microinjection or scrape-loading (el-Fouly et al., 1987), followed by observation of dye migration into neighboring cells. These methods are expensive and time-consuming, and introduce the complication of cellular damage (McKarns and Doolittle, 1992). In this communication we used a novel technique for measurement of dye transfer, termed in situ electroporation on a partly conductive slide (Raptis et al., 1994). This method takes advantage of the ability of short electric pulses to create transient "pores" in the cell membrane through which Lucifer yellow can enter simultaneously and into large numbers of cells with minimal disturbance to cellular physiology (Raptis et al., 1994; Brownell et al., 1996; Raptis and Vultur, 2001; Tomai et al., 1998). Cells are grown on a glass slide, half of which is coated with electrically conductive, optically transparent, indium-tin oxide. An electric pulse is applied in the presence of Lucifer yellow causing its penetration into cells growing on the conductive half of the slide. The migration of the dye through gap junctions into nonelectroporated cells growing on the nonconductive area is then microscopically observed under fluorescence illumination. The results demonstrate that primary Clara cells have low GJIC, which, however, increases within a few days of growth in culture. Unexpectedly, primary cells cultured from urethane-induced tumors, even at late stages of carcinoma development, also possessed extensive GJIC. However, further passage of these cells in culture led to a loss of junctional communication. These results suggest that, while the urethane-induced, molecular changes that are sufficient for tumor growth in vivo do not preclude junctional communication in cultured cells immediately after isolation, subsequent propagation in culture induces additional alterations that lead to gap junction closure.

\section{MATERIALS AND METHODS}

\section{Cell lines and culture techniques}

E10 is a mouse lung type II epithelial cell line that is nontumorigenic and exhibits contact-dependent inhibition of growth (Malkinson et al., 1997); E9 is a spontaneous transformant of E10 cells, selected for resistance to growth inhibition by dexamethasone. E9 cells are not contact inhibited, and upon subcutaneousinjection into immunocompetent, syngeneic mice, form tumors (Smith and Lykke, 1985; Malkinson et al., 1997). E10 and E9 cells were grown in CMRL 1066 medium (Gibco, Grand Island, NY) supplemented with $10 \%$ fetal calf serum (FCS). LM1, a cell line derived from a urethane-induced, solid lung tumor, and LM2, derived from a urethane-induced, papillary tumor, were grown in alpha-MEM supplemented with $10 \%$ fetal calf serum. PCC4 and 82-132, lines derived from mouse lung papillary and solid tumors, respectively, were grown in McCoy's and DMEM, respectively, supplemented with $10 \%$ FCS (Cesen-Cummings et al., 1998). All cells were grown as monolayers in plastic Petri dishes in a $5 \% \mathrm{CO}_{2}$ incubator and passaged by trypsinization.

\section{Isolation of bronchiolar Clara cells}

The technique described by Malkinson et al. (1993) was used with minor modifications. Briefly, two sets of five mice were anesthetized by intraperitoneal injection of $0.1 \mathrm{ml}$ pentobarbital/heparin. The chest was opened and a \#20 gauge Luer stub adaptor cannula inserted into the trachea and secured with suture silk. The abdominal aorta was severed and blood absorbed with sterile gauze. A perfusion needle, attached to a tuberculin syringe containing buffer A $(0.8 \% \mathrm{NaCl}, 5.5 \mathrm{mM} \mathrm{KCl}, 2.5 \mathrm{mM}$ sodium phosphate buffer $\mathrm{pH} 7.4,10.5 \mathrm{mM}$ HEPES $\mathrm{pH} 7.4,1$ $\mathrm{mg} / \mathrm{ml}$ glucose, $0.1 \%$ gentamicin), was inserted into the right ventricle of the heart, until it reached the pulmonary artery, and lungs were perfused with buffer A. At the same time, air was introduced into the lungs through the cannula, to inflate the lungs during perfusion. Lungs were subsequently removed from the thoracic cavity along with the cannulated trachea, placed in a tissue culture Petri dish containing buffer A supplemented with $2 \mathrm{mM}$ EGTA, and lavaged eight times with buffer A/EGTA through the tracheal cannula. Lungs were slowly filled with a total of $8 \mathrm{ml}$ of elastase solution $(4.3$ units $/ \mathrm{ml}$, Worthington Biochemical Corp., Freehold, NJ, in buffer B, $0.8 \%$ $\mathrm{NaCl}, 5.5 \mathrm{mM} \mathrm{KCl}, 2.5 \mathrm{mM}$ sodium phosphate buffer $\mathrm{pH} 7.4$, $10.5 \mathrm{mM}$ HEPES pH 7.4, $2 \mathrm{mM} \mathrm{CaCl} 2,1.5 \mathrm{mM} \mathrm{MgSO}_{4}, 1$ $\mathrm{mg} / \mathrm{ml}$ glucose, $0.1 \%$ gentamicin) through a syringe attached to the tracheal cannula. Lungs were subsequently cut away from the trachea and minced into approximately $1 \mathrm{~mm}^{3}$ pieces, which were placed into a sterile 250-ml Erlenmeyer flask containing $10 \mathrm{ml}$ of calf serum. The flask was gently shaken at $37^{\circ} \mathrm{C}$ for $20 \mathrm{~min}$, the suspension filtered through a nylon mesh, and centrifuged through a layer of calf serum $(2000 \times \mathrm{g}, 10 \mathrm{~min})$ in a 15-ml conical tube. Macrophages were removed by adsorption onto mouse IgG-coated plastic Petri dishes for $1 \mathrm{~h}$ at $37^{\circ} \mathrm{C}$. Clara cells were collected from the supernatant by centrifugation and plated on partly conductive slides or regular Petri dishes for further analysis. An aliquot was fixed by air drying and stained with nitroblue tetrazolium (NBT) (0.1\% NBT, $0.1 \%$ NADPH in HEPES-buffered saline, for $20 \mathrm{~min}$ ). More than $90 \%$ 
of the cells stained strongly the day after isolation (Malkinson et al., 1993).

\section{Induction of tumors in $A / J$ mice and growth of tumor-derived cells in culture}

An intraperitonealinjection of urethane was administered to 20 1-month-old male $\mathrm{A} / \mathrm{J}$ mice $(1 \mathrm{mg} / \mathrm{g}$ body weight, dissolved in $0.9 \% \mathrm{NaCl}$; Forkert et al., 1996). At 8, 16, and 40 weeks thereafter, six, seven, and seven mice, respectively, were sacrificed and the tumors sterilely dissected using a low-magnification, dissecting microscope. Several tumors from each mouse were minced into $\sim 1 \mathrm{~mm}^{3}$ pieces and cells separated by trypsinization. Trypsin was removed by centrifugation in DMEM containing 10\% FCS and the cells plated directly onto partly conductive slides for GJIC determination, or in Petri dishes in DMEM with $10 \%$ FCS. Because cell-cell contact is a prerequisite for the formation of gap junctions, the cells were plated at a relatively high-initial density (50-80\% of confluence). Upon reaching confluence, approximately 2-6 days later, GJIC was determined by electroporation in the presence of Lucifer yellow. Cytokeratin immunostaining using a polyclonal rabbit antikeratin antiserum (Dako, Z0622) indicated that the cells were of epithelial origin.

\section{Western blotting for connexin 43 quantitation}

This assay was performed as previously described (Dupont et al., 1988). Briefly, washed cells were lysed in $50 \mathrm{mM}$ Tris,
pH 8.0, $30 \mathrm{mg} / \mathrm{ml}$ SDS, $0.1 \mathrm{mM}$ leupeptin, $10 \mathrm{mg} / \mathrm{ml}$ aprotinin, and $1 \mathrm{mM}$ phenylmethylsulfonyl fluoride, and DNA was degraded by sonication. Protein concentration was determined by bicinchoninic acid assay (Pierce, Rockford, IL), and $30 \mu \mathrm{g}$ of protein resolved through polyacrylamide gel electrophoresis. Proteins were transferred to a polyvinylidine fluoride membrane (Millipore, Bedford, MA), the membrane probed for Cx43 using a monoclonal antibody (Chemicon, Temecula, CA), a horseradish-peroxidase-coupled, antimouse secondary antibody and ECL reagents according to the manufacturer's instructions.

\section{Examination of intercellular, gap junctional communication}

The technique described by Raptis et al. (1994, 2000) was used with minor modifications. Briefly, cells were grown on a glass slide, half of which was coated with electrically conductive, optically transparent indium-tin oxide, which permits growth of adherent cells (Fig. 1). A solution of the nonpermeant, fluorescent dye, Lucifer yellow $\left(5 \mathrm{mg} / \mathrm{ml}\right.$ in $\mathrm{Ca}^{++}$-free DMEM) was added to the cells. An electrode set was placed on top of the slide resting on the frame, linked to a circuit, and six pulses of $30-40 \mathrm{~V}$ were delivered from a $0.1 \mu \mathrm{F}$ capacitor. Cells were washed with $\mathrm{Ca}^{++}$-free DMEM, supplemented with $10 \%$ dialysed calf serum, and observed under phase contrast and fluorescence illumination using an Olympus IX70 inverted
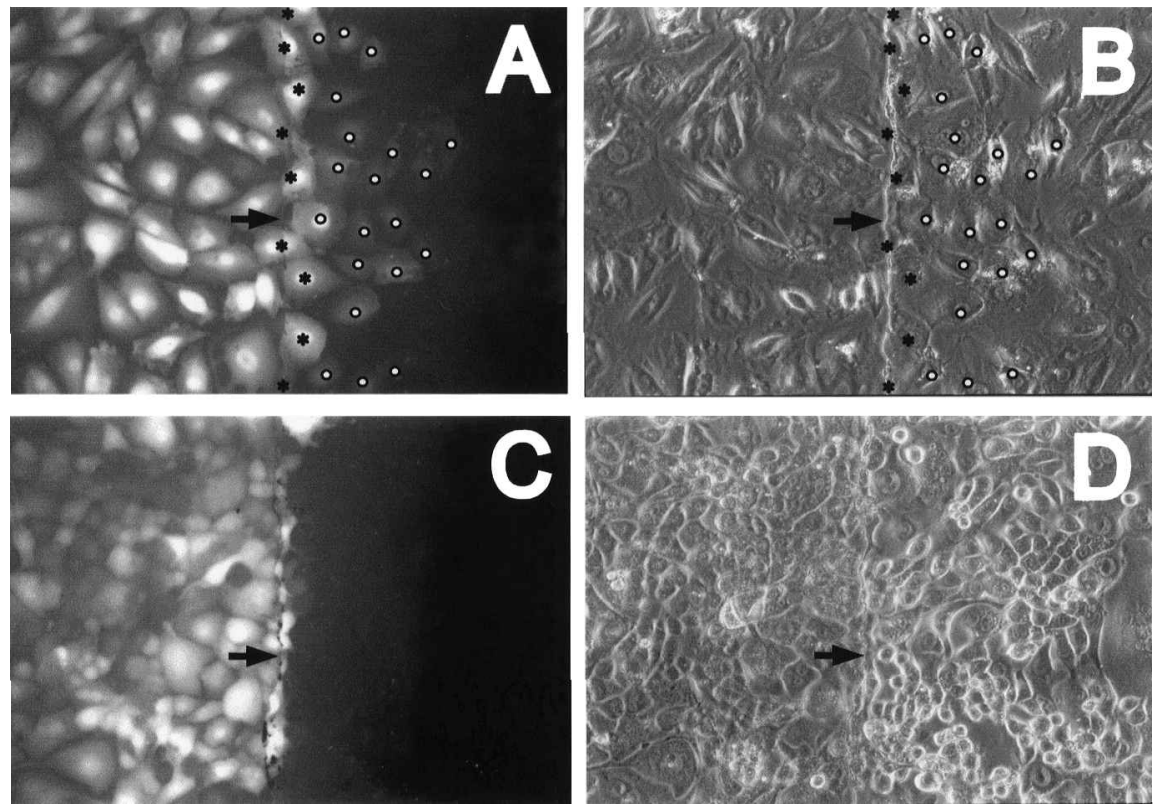

FIG. 1. GJIC in type II cell lines. (A, B) E10 cells established from mouse lung epithelial type II cells were plated on partly conductive slides and at confluence were electroporated in the presence of $5 \mathrm{mg} / \mathrm{ml}$ Lucifer yellow. After washing away any unincorporated dye, cells from the same field were photographed under fluorescence (A) or phase contrast (B) illumination (Raptis et al., 1994). Note the gradient of fluorescence, indicating dye transfer through gap junctions. To quantitate intercellular communication, the number of cells into which the dye transfered through gap junctions per electroporated border cell was calculated by dividing the total number of fluorescing cells on the nonconductive side (white circles) by the number of cells growing at the border with the conductive coating (black stars) (Raptis et al., 1994). (C, D) E9 cells, a spontaneous transformant of the E10 line, were plated on partly conductive slides, electroporated, washed and photographed as above. (C) fluorescence, (D) phase contrast illumination photograph of the same field. Note the absence of dye transfer through gap junctions. To better illustrate these differences, dense cultures of both types of cells are shown. In all photographs, the left side is conductive. Arrows on the conductive side point to the interphase between conductive and non-conductive areas. Magnification: $140 \times$. 
phase contrast microscope equipped with epifluorescence. Lucifer yellow tracer movement was evaluated 5 min after the electrical pulse by overlapping the phase contrast and fluorescence images of the cells. Cells growing on the conductive side of the slide are electroporated, while those on the neighboring, nonconductive area do not receive any current, therefore are not permeated (Raptis et al., 1994). The dye can only enter these cells from electroporated adjacent cells through gap junctions, if any are present. To maximize the likelihood that cells will attach close to the border between conductive and nonconductive areas, this transition line ran laterally across the slide, as described before (Raptis et al., 2000). The equipment is available from Ask Science Products, Kingston, Ontario, Canada.

To quantitate intercellular communication, the number of cells into which the dye migrated through gap junctions per electroporated border cell was calculated by dividing the total number of fluorescing cells on the nonconductive side by the number of cells growing at the border with the conductive coating (Fig. 1A). For each experiment, transfer from a minimum of 200 contiguous border cells was calculated. Results from at least eight separate slides are presented as means \pm SEM. This number is referred to as GJIC.

\section{RESULTS}

\section{GJIC in established lung epithelial cell lines}

E10 is an established, type II mouse alveolar epithelial cell line. Previous work, using microinjection of the fluorescentdye, Lucifer yellow, indicated that a large proportion of these cells possess gap junctions (Cesen-Cummings et al., 1998). To pre-

Table 1. GJiC ${ }^{\mathrm{a}}$ in Normal and Transformed Mouse Lung Type II Cell Lines and Cells Derived from Urethane-Induced Tumors

E10

E9

LM1

LM2

PCC4

82-132

Clara cells

Clara cells

Lung hyperplasia

Lung adenoma

Lung carcinoma
Established lines

Type II, normal, immortalised

Spontaneous transformant of E10

Solid tumor-derived, slow growing

Papillary tumor-derived, fast growing

Papillary tumor-derived, fast growing

Solid tumor-derived, fast growing

Primary cells

I. Normal cells

2 days after isolation

10 days after isolation

$0.3 \pm 0.2$

$2.1 \pm 0.2$

II. Tumor cells ${ }^{\mathrm{b}}$

8 weeks after urethane injection

16 weeks after urethane injection

40 weeks after urethane injection

$2.7 \pm 0.2$

$2.5 \pm 0.2$

$2.5 \pm 0.2$

Carcinoma cells, grown in culture ${ }^{\mathrm{c}}$

3 weeks in culture

6 months in culture

6 months in culture

8 months in culture

8 months in culture

4 months in culture

4 weeks in culture

$2.5 \pm 0.2$

$0.6 \pm 0.2$

$0.2 \pm 0.1$

$0.3 \pm 0.2$

$0.2 \pm 0.1$

$0.7 \pm 0.2$

$1.5 \pm 0.2$

5.5 months in culture

$0.5 \pm 0.2$

6 months in culture

$1.0 \pm 0.2$

6 months in culture

$1.1 \pm 0.2$

5 months in culture (mixed clones)

6 months in culture (mixed clones)
$0.7 \pm 0.2$

$0.5 \pm 0.2$

M1-mix

${ }^{\mathrm{a}}$ GJIC was calculated as described in Fig. 1A, by dividing the total number of fluorescing cells on the nonconductive side, where the dye transferred through gap junctions (white dots, Fig. 1A and Materials and Methods), by the number of cells growing at the border with the conductive coating, which were loaded with the dye by electroporation (black stars). Numbers refer to means \pm SEM.

${ }^{\mathrm{b}}$ Following urethane administration, tumors were explanted at the indicated times and cells placed in culture. Results from one representative tumor each, 3 days after plating are shown.

${ }^{c}$ Cloned carcinoma cells were grown in culture for the indicated times and their GJIC determined as above. 
cisely quantitate GJIC, cells were plated on partly conductive slides and electroporated in the presence of Lucifer yellow, as described in Materials and Methods. This technique offers the possibility of observing intercellular communication among large numbers of cells simultaneously, which permits accurate assessment of the degree of intercellular communication; fol- lowing pulse delivery, the number of cells into which the dye transfered, per cell loaded with the dye by electroporation, was calculated by dividing the total number of fluorescing cells on the nonconductive area (Fig. 1A and B, marked with a dot) by the number of cells growing on the conductive side, at the border with the nonconductive area (Fig. 1A and B, marked with
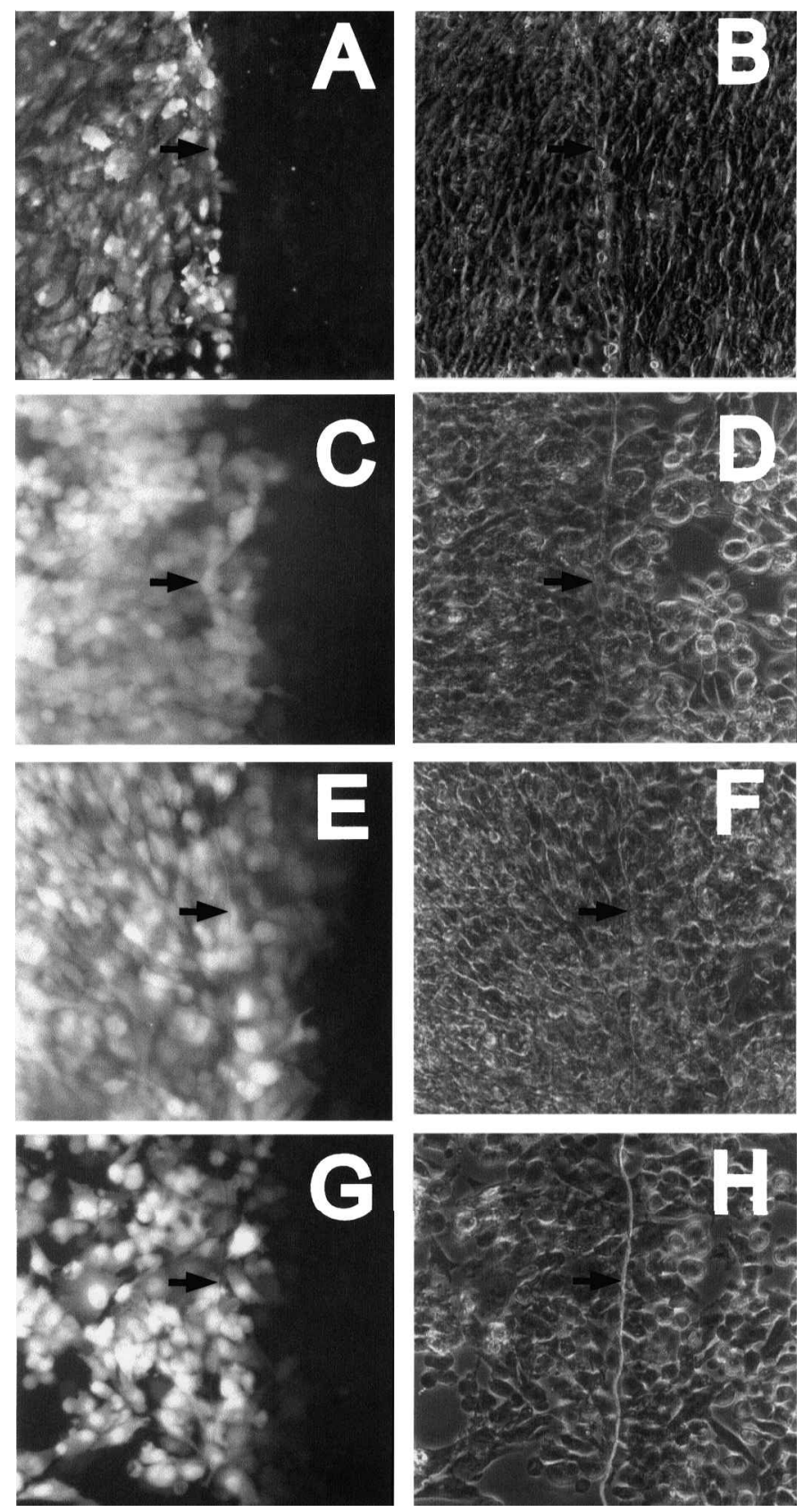

FIG. 2. GJIC in primary Clara cells and cells from urethane-induced tumors. (A, B) Primary Clara cells 2 days following isolation were plated on partly conductive slides and electroporated in the presence of $5 \mathrm{mg} / \mathrm{ml}$ Lucifer yellow, as described in Fig. 1 . Note the absence of dye transfer through gap junctions. (C, D) Primary Clara cells 10 days following isolation and growth in culture were plated on partly conductive slides and electroporated in the presence of $5 \mathrm{mg} / \mathrm{ml}$ Lucifer yellow as described in Fig. 1 . Note the extensive dye transfer through gap junctions. (E, F) Cells from urethane-inducedlung carcinomas were plated on partly conductive slides and 3 days after plating, dense cultures electroporated in the presence of $5 \mathrm{mg} / \mathrm{ml}$ Lucifer yellow as described in Fig. 1. Note the extensive dye transfer through gap junctions. $(\mathbf{G}, \mathbf{H})$ Cells from urethane-induced lung carcinomas were plated on partly conductive slides and electroporated at lower densities than in E and F, $12 \mathrm{~h}$ after plating, in the presence of $5 \mathrm{mg} / \mathrm{ml} \mathrm{Lucifer} \mathrm{yellow} \mathrm{as} \mathrm{described}$ in Fig. 1. Note the less extensive dye transfer through gap junctions. Magnification: $140 \times$. 
a star). As previously shown (Raptis and Vultur, 2001), a wide range of voltages $(25-45 \mathrm{~V})$ permitted efficient introduction of Lucifer yellow into all lines tested with no detectable cellular damage and no effect upon GJIC (Raptis et al., 1994, 1998; Raptis and Vultur, 2001). In addition, results obtained using this method closely correlate with results obtained using more conventional techniques, such as scrape-loading (Raptis et al., 1994). As shown in Figure 1, transfer into several rows of E10 cells was evident (GJIC of $2.7 \pm 0.2$ ), as revealed by the distinct gradient of fluorescence from the cells at the edge of the conductive border, to the nonconductive area. This degree of junctional communication is similar to that previously seen in the rat fibroblast line, F111 (Raptis et al., 1994). In contrast, GJIC in line E9, the spontaneous transformant of E10 (Smith et al., 1984), was very low $(0.2 \pm 0.1$, Fig. 1 and Table 1$)$, indicating that spontaneous transformation of E10 cells dramatically decreases GJIC.

\section{Gap junctional communication in primary Clara cell isolates and cells derived from urethane-induced tumors}

Expression of connexin 43, a prevalent connexin in pulmonary epithelial cells, is elevated in lung adenomas induced in mouse lung upon urethane injection, compared to uninvolved lung tissue or normal lung, then reduced in carcinomas (Ruch et al., 2001). Given that connexins may possess other functions in the cell, in addition to the formation of gap junction channels (Ruch, 2000), direct GJIC examination would be a better measure of cell to cell transfer than connexin content alone. Besides, because the uninvolved tissue and normal lung possess additional cell types to those that proliferate to give rise to the tumors, to follow the effect of tumor progression upon gap junctions, it is important to compare GJIC in the progenitor Clara and type II cells, and hyperplasias, adenomas, and carcinomas. Examination of GJIC in primary Clara cells from untreated mice immediately after isolation revealed very low levels of junctional communication (Fig. 2A and B and Table 1). No transfer was detected between Clara cells and any of the small number of fibroblasts present (not shown). However, as previously shown for rat type II cells (Lee et al., 1997), Clara cells progressively acquired a more extended morphology upon culture from their initial more rounded appearance, and by day $10 \mathrm{had}$ extensive GJIC (2.1 \pm 0.2 , Fig. 2C and D). As previously documented (Malkinson et al., 1993), nitroblue tetrazolium reduction to the insoluble purple formazan (Devereux and Fouts, 1980) was very strong in Clara cells during the first day in culture but gradually waned, although it remained present. Cells continued to stain more strongly than mesenchymal cell lines (not shown), indicating that the main cell type present in longterm cultures is Clara cells. As expected, Clara cell cultures stained strongly for cytokeratins.

Tumors produced at different times after urethane injection were excised and the cells plated on partly conductive slides. As shown in Table 1, cells from hyperplasias and adenomas appearing at 8 and 16 weeks, respectively, had extensive GJIC $(2.7 \pm 0.2$ and $2.5 \pm 0.2$, respectively). Unexpectedly, as also shown in Fig. 2 ( $\mathrm{E}$ and F, G and $\mathrm{H}$ ), cells grown from carcinomas appearing at 40 weeks or even later after urethane administration also had extensive junctional communication. This observation is consistent with the high levels of connexin 43 previously noted in urethane-induced carcinomas in $\mathrm{A} / \mathrm{J}$ mice and may imply that the molecular changes that lead to the formation of a tumor in vivo, are not able to interrupt gap junctions in cells cultured from these tumors. Consistent with earlier observations(Chaudhuri et al., 1993, Lee et al., 1997), GJIC was lower in cells within a few hours after passage onto the conductive slides (Fig. 2G and $\mathrm{H}$ ) but increased dramatically upon subsequent growth to confluence, permitting extensive cell-cell contact (Fig. 2E and F). Similar results were obtained with cells from all mice bearing hyperplasias, adenomas, or carcinomas (not shown).

Explanted carcinoma cells were propagated in culture for several months and their junctional communication examined before and after isolation of individual clones (Table 1). Contrary to primary tumor cells, eight clones that were derived from cells cultured from carcinomas that had been dissected from five individual mice had dramatically reduced GJIC levels after 5-6 months in culture (approximately 0.2 to 1.1 , Table 1 ), while seven clones derived from three different mice had levels of 1 to $1.5 \pm 0.3$ (not shown). A substantial reduction in GJIC was also seen in mixed populations of tumor cells, prior to cloning (Table 1). As another estimate of junctional permeability, we examined connexin- 43 content in a number of lines. As shown in Figure 3, there was an excellent correlation between connexin-43 levels and Lucifer yellow dye transfer, using our assay. These results are in agreement with data from the tumor-derived, established cell lines LM1, LM2, PCC4, and 82-132 (Table 1). The extensive communication of primary carcinoma cells is in sharp contrast to the absence of GJIC in the majority of the established tumor lines (e.g., E9, Fig. 1C and D), and indicates that propagation in culture appears to be a

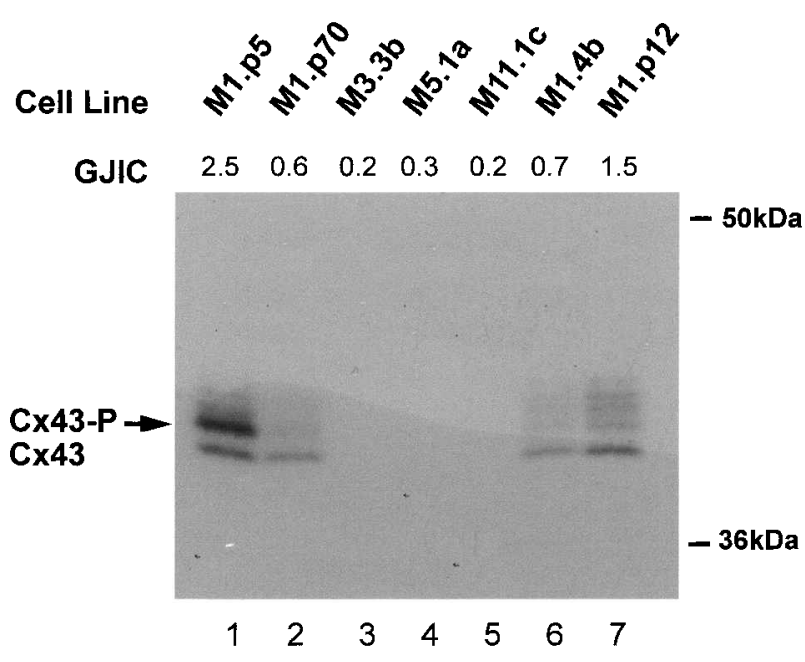

FIG. 3. Connexin-43 quantitation. Total protein extracts from the lines indicated at the top (Table 1) were resolved by polyacrylamide gel electrophoresis and proteins transferred to a $\mathrm{Ni}$ trocellulose membrane, which was probed with an antibody against connexin-43 (see Materials and Methods). GJIC: numbers correspond to Lucifer yellow transfer assessed by in situ electroporation (Table 1). Arrows point to the positions of connexin-43 (Cx43) or its phosphorylated form (Cx43-P). Horizontal bars point to the positions of molecular weight markers. 
necessary step for gap junction closure of urethane-induced, lung tumor cells.

\section{DISCUSSION}

Extensive evidence from a number of cell culture systems has demonstrated a correlation between low GJIC levels and neoplasia. Oncogene proteins, such as Src, the middle tumor antigen of polyoma virus (mT) (Azarnia and Loewenstein, 1987; Raptis et al., 1994) and Ras (De Feijter et al., 1992; Brownell et al., 1996), as well as tumor promoting agents (Oh et al., 1993) interrupt junctional permeability in a variety of cultured cells derived from mouse or rat. Moreover, using systems of inducible mT or v-Ras expression, it was demonstrated that the levels of these oncogenes, which are sufficient to block gap junctions, are lower than those required for full neoplastic conversion and tumorigenicity (Raptis et al., 1994; Brownell et al., 1997). In addition, overexpression of pp60 ${ }^{\mathrm{c}-\mathrm{src}}$, which does not lead to full neoplastic transformation, is able to interrupt GJIC (Azarnia et al., 1988). These results imply that a decrease in GJIC may be an important early event preceding full neoplastic conversion at least in these in vitro systems.

We attempted to establish the stage in tumor development in vivo when gap junctional communication is interrupted, using the well-studied model of urethane-induced tumors in $\mathrm{A} / \mathrm{J}$ mice. Previous results indicated that a mutationally activated $\mathrm{Ki}$-Ras oncogene, and inactivated or deleted forms of the p53 tumor suppressor gene occur in urethane-induced tumors with a high frequency; Ki-Ras mutations are already present in most hyperplasias and adenomas, while p53 mutations appear at later stages (Horio et al., 1996). Our results revealed that although junctional communication is eliminated in type II cells upon spontaneous transformation in culture (e.g., line E9) (CesenCummings et al., 1998), primary cultures from urethane-induced lung tumors, even at late stages of tumor development, possess extensive junctional permeability. These data are in agreement with findings indicating that connexin-43 is expressed in both benign and malignant lung tumors (Ruch et al., 2001). However, repeated passage of the tumor cells in culture reduced GJIC and connexin-43 levels. Therefore, it appears that the mutations present in urethane-induced carcinomas are not sufficient to interrupt gap junctions in cells isolated from these tumors; additional changes brought about through passage in culture, possibly enhanced Ras expression (Finney and Bishop, 1993; Fisher et al., 2001), are required for this effect.

A rapid, precise, and efficient method of GJIC measurement is especially important for GJIC quantitation in primary cells, because a considerable degree of variation might be expected. The technique described here can assess GJIC in a large number of cells simultaneously without cellular injury (Brownell et $a l ., 1998)$, and it does not involve any mechanical manipulation of the cells that could disturb cell-to-cell contact areas and interrupt gap junctions. Previous results (Cesen-Cummings et al., 1998) using microinjection of Lucifer yellow found that approximately $90 \%$ of E10 and $20 \%$ of E9 cells had gap junctions; our corresponding numbers using in situ electroporation are $2.7 \pm 0.2$ and $0.2 \pm 0.1$ (Table 1). This apparent discrepancy in absolute values is probably related to differences in experimental approach. When Lucifer yellow is microinjected into cells growing as a monolayer, transfer from a single cell is assessed; cells score as positive if any transfer is observed. In the present study, on the other hand, transfer from cells lined up along the edge of the conductive coating is measured, so that quantitation of the average dye transfer from a large number of cells in the population can be precisely achieved. In addition, contrary to electroporation, which opens a large number of small pores in the cell membrane that immediately reclose, microinjection can cause damage to the cell that could affect junctional communication. In any event, our results indicate that mutations caused by urethane administration that lead to neoplastic growth in vivo, do not cause a concomitant interruption of GJIC in cells grown from these tumors; other molecular changes occurring during passage in culture are required for GJIC loss. The nature of these alterations will be the subject of future investigations.

\section{ACKNOWLEDGMENTS}

The authors would like to thank Kevin Firth, P. Eng. (Ask Science Products Inc.), for providing the electroporation equipment and valuable advice, and Normand Marceau for valuable advice about cytokeratin staining. This work was supported by the Cancer Research Society Inc. (L.R.), the Natural Sciences and Engineering Research Council of Canada (L.R.), the Canadian Institutes of Health Research (L.R.), the Advisory Research Committee of Queen's University (L.R.), by USPHS Grant CA33497 (A.M.), and NCIC (P.G.F.). A.V. is the recipient of a studentship from the Natural Sciences and Engineering Research Council of Canada, and an Ontario Graduate studentship, a Queen's University graduate award and a Queen's University travel grant. E.T. is the recipient of a Queen's University graduate award, a studentship from the Natural Sciences and Engineering Research Council of Canada, and awards from the Thoracic Society and the Lemos foundation.

\section{REFERENCES}

AZARNIA, R., and LOEWENSTEIN, W.R. (1987). Polyomavirus middle $t$ antigen downregulates junctional cell-to-cell communication. Mol. Cell. Biol. 7, 946-950.

AZARNIA, R., and RUSELL, T.R. (1985). Cyclic AMP effects on cellto-cell junctional membrane permeability during adipocytic differentiation of 3T3-L1 fibroblasts. J. Cell Biol. 100, 265-269.

AZARNIA, R., REDDY, S., KMIECIK, T.E., SHALLOWAY, D., and LOWENSTEIN, W.R. (1988). The cellular src gene product regulates junctional cell to cell communication. Science 239, 398-400.

BROWNELL, H.L., LYDON, N., SCHAEFER, E., ROBERTS, T.M., and RAPTIS, L. (1998). Inhibition of epidermal growth factor-mediated ERK1/2 activation by in situ electroporation of nonpermeant [(alkylamino)methyl]acrylophenone derivatives. DNA \& Cell Biol. 17, 265-274.

BROWNELL, H.L., NARSIMHAN, R., CORBLEY, M.J., MANN, V.M., WHITFIELD, J.F., and RAPTIS, L. (1996). Ras is involved in gap junction closure in mouse fibroblasts or preadipocytes but not in differentiated adipocytes. DNA Cell Biol. 15, 443-451.

BROWNELL, H.L., WHITFIELD, J.F., and RAPTIS, L. (1997). Elimination of intercellular junctional communication requires lower Ras ${ }^{\text {leu61 }}$ levels than stimulation of anchorage-independent proliferation. Cancer Detect. Prev. 21, 289-294. 
BRUZZONE, R., WHITE, T.W., and PAUL, D.L. (1996). Connections with connexins: The molecular basis of direct intercellular signalling. Eur. J. Biochem. 238, 1-27.

CESEN-CUMMINGS, K., FERNSTROM, M.J., MALKINSON, A.M., and RUCH, R.J. (1998). Frequent reduction of gap junctional intercellular communication and connexin-43 expression in human and mouse lung carcinoma cells. Carcinogenesis 19, 61-67.

CHAUDHURI, R., SIGLER, K., DUPONT, E., TROSKO, J.E., MALKINSON, A.M., and RUCH, R.J. (1993). Gap junctional intercellular communication in mouse lung epithelial cell lines: Effects of cell transformation and tumor promoters. Cancer Lett. 71, 11-18.

CHEN, B., JOHANSON, L., WIEST, J.S., ANDERSON, M.W., and YOU, M. (1994). The second intron of the K-ras gene contains regulatory elements associated with mouse lung tumor susceptibility. Proc. Nat. Acad. Sci. USA 91, 1589-1593.

DE FEIJTER, A.W., TROSKO, J.E., KRIZMAN, D.B., LEBOVITZ, R.M., and LIEBERMAN, M.W. (1992). Correlation of increased levels of Ha-ras T24 protein with extent of loss of gap junction function in rat liver epithelial cells. Mol. Carcinog. 5, 205-212.

DEVEREUX, T.R., and FOUTS, J.R. (1980). Isolation and identification of Clara cells from rabbit lung. In vitro 16, 958-968.

DUPONT, E., EL AOUMARI, A., ROUSTIAU-SEVERE, S., BRIAND, J.P., and GROS, D. (1988). Immunological characterization of rat cardiac gap junctions: Presence of common antigenic determinants in heart of other vertebrate species and in various organs. J. Membr. Biol. 104, 119-128.

EL-FOULY, M.H., TROKSO, J.E., and CHANG, C.C. (1987). Scrapeloading and dye transfer: A rapid and simple technique to study gap junctional intercellular communication. Exp. Cell Res. 168, 442-430.

FINNEY, R.E., and BISHOP, J.M. (1993). Predisposition to neoplastic transformation caused by gene replacement of H-ras1. Science 260, 1524-1527.

FISHER, G.H., WELLEN, S.L., KLIMSTRA, D., LENCZOWSKI, J.M., TICHELAAR, J.W., LIZAK, M.J., WHITSETT, J.A., KORETSKY, A., and VARMUS, H.E. (2001). Induction and apoptotic regression of lung adenocarcinomas by regulation of a K-Ras transgene in the presence and absence of tumor suppressor genes. Genes Dev. 15, 3249-3262.

FORKERT, P.G., JACKSON, A.C., PARKINSON, A., and CHEN, S. (1996). Diminished expression of CYP1A1 in urethane-induced lung tumors in strain A/J mice: Analysis by in situ hybridization and immunohistochemical methods. Am. J. Respir. Cell Mol. Biol. 14, 444-453.

GOODENOUGH, D.A., GOLIGER, J.A., and PAUL, D.L. (1996). Connexins, connexons, and intercellular communication. Annu. Rev. Biochem. 65, 475-502.

HORIO, Y., CHEN, A., RICE, P., ROTH, J.A., MALKINSON, A.M., and SCHRUMP, D.S. (1996). Ki-ras and p53 mutations are early and late events, respectively, in urethane-induced pulmonary carcinogenesis in A/J mice. Mol. Carcinog. 17, 217-223.

LEE, Y.C., YELLOWLEY, C.E., LI, Z., DONAHUE, H.J., and RANNELS, D.E. (1997). Expression of functional gap junctions in cultured pulmonary alveolar epithelial cells. Am. J. Physiol. 272, L1105-L1114.

MALKINSON, A.M. (1992). Primary lung tumors in mice: An experimentally manipulable model of human adenocarcinoma. Cancer Res. 52, 2670s-2676s.

MALKINSON, A.M. (2001). Primary lung tumors in mice as an aid for understanding, preventing, and treating human adenocarcinoma of the lung. Lung Cancer 32, 265-279.

MALKINSON, A.M., DWYER-NIELD, L.D., RICE, P.L., and DINSDALE, D. (1997). Mouse lung epithelial cell lines-Tools for the study of differentiation and the neoplastic phenotype. Toxicology 123, 53-100.

MALKINSON, A.M., MILEY, F.B., CHICHESTER, C.H., and PLOPPER, C.G. (1993). Isolation of noncilliated bronchiolar (Clara) epithelial cells from mouse lung. Methods Toxicol. 1A, 123-133.
MCDONAGH, D., VOLLMER, R.T., and SHELBURNE, J.D. (1991). Intercellular junctions and tumor behavior in lung cancer. Mod. Pathol. 4, 436-440.

MCKARNS, S.C., and DOOLITTLE, D.J. (1992). Limitations of the scrape-loading/dye transfer technique to quantify inhibition of Gap junctional, Intercellular communication. Cell Biol. Toxicol. 8, 89-103.

OH, S.Y., GRUPEN, C.G., and MURRAY, A.W. (1993). Phorbol ester induces phosphorylation and down-regulation of connexin 43 in WB cells. Biochim. Biophys. Acta 1094, 243-245.

RAPTIS, L., and VULTUR, A. (2001). Neoplastic transformation assays. In: SV40 Protocols, L. Raptis, ed. (Humana Press Inc., Clifton, NJ) pp. 151-164.

RAPTIS, L., BROWNELL, H.L., FIRTH, K.L., and GIORGETTIPERALDI, S. (1998). In situ electroporation for the study of signal transduction. In Cell Biology: A Laboratory Handbook, J.C. Celis, ed. (Academic Press Inc., New York) pp. 75-87.

RAPTIS, L., BROWNELL, H.L., FIRTH, K.L., and MACKENZIE, L.W. (1994). A novel technique for the study of intercellular, junctional communication: Electroporation of adherent cells on a partly conductive slide. DNA Cell Biol. 13, 963-975.

RAPTIS, L., TOMAI, E., and FIRTH, K.L. (2000). Improved procedure for examination of gap junctional, intercellular communication by in situ electroporation on a partly conductive slide. Biotechniques 29, 222-226.

RUCH, R.J. (2000). Role of gap junctions in cellular growth control and neoplasia: Evidence and mechanisms. Curr. Top. Membr. 49, 535-554.

RUCH, R.J., PORTER, S., KOFFLER, L.D., DWYER-NIELD, L.D., and MALKINSON, A.M. (2001). Defective gap junctional intercellular communication in lung cancer: Loss of an important mediator of tissue homeostasis and phenotypic regulation. Exp. Lung Res. 27, 231-243.

SMITH, G.J., and LYKKE, A.W. (1985). Characterization of a neoplastic epithelial cell strain derived by dexamethasone treatment of cultured normal mouse type 2 pneumocytes. J. Pathol. 147, $165-172$.

SMITH, G.J., LE MESURIER, S.M., DE MONTFORT, M.L., and LYKKE, A.W. (1984). Development and characterization of type 2 pneumocyte-related cell lines from normal adult mouse lung. Pathology 16, 401-405.

THAETE, L.G., GUNNING, W.T., STONER, G.D., and MALKINSON, A.M. (1987). Cellular derivation of lung tumors in sensitive and resistant strains of mice: Results at 28 and 56 weeks after urethane treatment. J. Natl. Cancer Inst. 78, 743-749.

TOMAI, E., BROWNELL, H.L., TUFESCU, T., REID, K., and RAPTIS, L. (1999). Gap junctional communication in lung carcinoma cells. Lung Cancer 23, 223-231.

TOMAI, E., BROWNELL, H.L., TUFESCU, T., REID, K., RAPTIS, S., CAMPLING, B.G., and RAPTIS, L. (1998). A functional assay for intercellular, junctional communication in cultured human lung carcinoma cells. Lab. Invest. 78, 639-640.

Address reprint requests to: Leda Raptis, Ph.D.

Department of Microbiology and Immunology Queen's University

Botterell Hall, Rm. 715

Kingston, Ontario, Canada K7L3N6

E-mail: raptis1@post.queensu.ca

Received August 19, 2002; received in revised form September 1, 2002; accepted September 9, 2002. 